\title{
B6 Análise do rendimento do complexo produtivo dos soros hiperimunes do Instituto Vital Brazil (IVB)
}

Aniesse Silva Aguiar ${ }^{1}$, Larissa de Oliveira Valadares², Michelle Pacheco de Lima ${ }^{1}$, Moacir de Souza Silva ${ }^{1}$, Jorge Luiz Coelho Mattos ${ }^{1}$

${ }^{1}$ Instituto Vital Brazil

2 Famath - PIBIC

Introdução: Segundo a ANVISA, soros hiperimunes são imunoglobulinas heterólogas inteiras ou fragmentadas, purificadas, obtidas de plasma de animais hiperimunizados com toxinas de animais, microorganismos ou vírus.

Objetivo: Este estudo objetivou avaliar a eficiência da imunização, purificação e concentração dos soros do IVB.

Metodologia: Foram pesquisadas e analisadas as fichas de 67 lotes de produção dos soros fabricados entre 2008 e 2012 para os cálculos dos rendimentos.

Resultados: Os resultados de rendimento quanto à potência $x$ volume de plasma hiperimune e gamaglobulina concentrada, são expressos nas médias percentuais de recuperação das imunoglobulinas: soro Antibotrópico $(27,50 \% \quad \pm 0,04)$; Anticrotálico $(37,78 \% \pm 0,09)$; Antibotrópico-crotálico (fração antibotrópica $26,85 \% \pm 0,11$ e fração anticrotálica 50,75\% \pm 0,05); Antiescorpiônico (19,46\% $\pm 0,05)$; Antitetânico $(32,05 \% \pm 0,07)$ eAntirrábico (aproximadamente de $4,70 \%$ ). Dificuldades de obtenção de antígenos para os soros antilaquéticos e antirrábicos nem sempre permitiram a determinação de potência dos plasmas hiperimunes correspondentes, o que tornou inconsistente o cálculo percentual médio de recuperação destas imunoglobulinas. Os cálculos de rendimento mostram a produtividade (ampolas/equino/ano) com as seguintes médias: soro Antitetânico

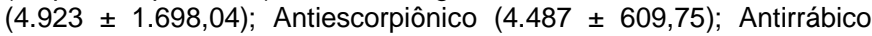
(3.968 $\pm 651,36)$; Antibotrópico (2.965 $\pm 257,90)$; Anticrotálico (1.676,5 $\pm 143,75)$; Antibotrópico-laquético $(609,75 \pm 180,66)$ e Antibotrópicocrotálico $(530 \pm 89,00)$. Os maiores rendimentos de ampolas/equino encontrados foram no Antitetânico, Antiescorpiônico e Antirrábico. A aparente contradição com os resultados acima expressados deve-se ao fato de que as ampolas dos soros Antitetânico, Antiescorpiônico e Antirrábico contém um volume de $5 \mathrm{ml}$, enquanto os soros antiofídicos (Antibotrópico; Anticrotálico; Antibotrópico-laquético e Antibotrópicocrotálico) são apresentados em ampolas de $10 \mathrm{ml}$. Portanto duas ampolas dos primeiros correspondem a uma dos últimos. Por outro lado observamos que dos soros antiofídicos, o Antibotrópico-laquético e Antibotrópico-crotálico são os de menor rendimento em número de ampolas /equino, o que se explica pelo fato de que compreendem dois tipos de antígenos que são inoculados em equídeos diferentes (na 
imunização) e produzidos separadamente, para posterior mistura em uma única ampola. Observamos também diferenças no rendimento entre os mesmos tipos de soros. Estas variações parecem ser indicativas de heterogeneidades no processo de produção, que podem ir desde variabilidades no manejo dos equídeos, a inconstâncias no processo fabril, obsolescência da malha industrial, ou ainda devido às peculiaridades imunogênicas dos soros. A hidrólise das diferentes formas de $\lg G$ não é homogênea, na $\lg G(T)$ ocorre mais rapidamente do que na $\operatorname{lgGa}$, e portanto soros cuja neutralização dependam fundamentalmente da primeira estariam sendo mais degradados, resultando num menor rendimento.

Conclusão: Entendemos ser oportuna a revisão e as adequações metodológicas segundo cada tipo de soro a ser produzido, de forma a aperfeiçoar o processo e aumentar o rendimento das imunoglobulinas purificadas. Em face destas considerações, a unidade de purificação e concentração de soros do IVB vem sendo renovada em todo seu processo fabril desde 2013.

Palavras-Chave: Imunobiológicos, Purificação de Imunoglobulinas, Aniticorpos 